\title{
COVID-19 and the liver: a narrative review of the present state of knowledge
}

\author{
Ragesh B. Thandassery ${ }^{1,2}$, Jonathan A. Dranoff ${ }^{1,2}$, Abhilash Perisetti ${ }^{1,2} \wedge$, Tamar Taddei $^{3,4} \wedge$ \\ ${ }^{1}$ Division of Gastroenterology, Department of Medicine, Central Arkansas Veteran Healthcare System, Little Rock, AR, USA; ${ }^{2}$ Division of \\ Gastroenterology, Department of Medicine, University of Arkansas for Medical Sciences, Little Rock, AR, USA; ${ }^{3}$ Section of Digestive Diseases, \\ Department of Medicine, VA Connecticut Healthcare System, New Haven, CT, USA; ${ }^{4}$ Section of Digestive Diseases, Department of Medicine, Yale \\ School of Medicine, Yale University, New Haven, CT, USA \\ Contributions: (I) Conception and design: RB Thandassery, JA Dranoff, T Taddei; (II) Administrative support: RB Thandassery, JA Dranoff, T Taddei; \\ (III) Provision of study materials or patients: All authors; (IV) Collection and assembly of data: All authors; (V) Data analysis and interpretation: All \\ authors; (VI) Manuscript writing: All authors; (VII) Final approval of manuscript: All authors. \\ Correspondence to: Ragesh B. Thandassery, MD. Division of Gastroenterology, Department of Medicine, Central Arkansas Veteran Healthcare \\ System, Little Rock, AR, USA. Email: ragesh.thandassery@va.gov.
}

\begin{abstract}
Novel corona virus disease (COVID-19) is an ongoing pandemic that has spread across the globe. The virus primarily infects type-2 pneumocytes in alveoli and causes lung disease, with severity ranging from mild pneumonia to acute respiratory distress syndrome. The virus also invades gastrointestinal epithelial cells, hepatocytes, and biliary epithelial cells. Derangement of liver function tests is noted in about one third of patients and appears to correlate with more severe disease. There are multiple mechanisms by which the virus can cause liver injury; immune-mediated inflammation and direct viral cytotoxicity are believed to be the predominant mechanisms. Liver injury appears to be transient, usually recovering with resolution of illness. Limited available studies and experience from prior corona virus pandemics seem to suggest that immunosuppressed patients have similar outcomes compared to non-immunosuppressed patients. Age and comorbid conditions seem to influence outcome, irrespective of immune status. Additionally, patients with preexisting comorbid conditions are more prone to acquire infection and should strictly adhere to travel and social distancing advisories. Telemedicine should be utilized to provide uninterrupted care for patients with liver disease, and clinic or hospital visits should be advised only in sick patients with advanced liver disease. In conclusion, liver dysfunction is not uncommon in COVID-19, it generally improves with resolution of disease, and patients with chronic liver disease (CLD) need continued follow up, uninterrupted by the ongoing pandemic, preferably in virtual clinic settings.
\end{abstract}

Keywords: COVID-19; liver disease; hepatotoxicity; liver transplantation

Received: 09 June 2020; Accepted: 22 September 2020; Published: 25 October 2022.

doi: $10.21037 /$ tgh-20-243

View this article at: http://dx.doi.org/10.21037/tgh-20-243

\footnotetext{
^ ORCID: Ragesh B. Thandassery, 0000-0002-5357-4847; Jonathan A. Dranoff, 0000-0002-2439-4759; Abhilash Perisetti, 0000-00034074-6395; Tamar Taddei, 0000-0002-6500-1739.
} 


\section{Introduction ${ }^{1}$}

Novel corona virus disease (COVID-19) caused by severe acute respiratory syndrome Coronavirus-2 (SARS-CoV-2) has claimed over 750,000 lives globally as of August 14, 2020 (1). The pandemic has now extended to more than 180 countries, with the maximum number of cases reported from the US, followed by Brazil, India and Russia $(1,2)$. COVID-19 usually results in mild lung infection but can lead on to life threatening acute respiratory distress syndrome, and the overall mortality is roughly $2.3 \%(3-5)$. Advanced age, hypertension, coronary artery disease, diabetes mellitus, and chronic lung disease are risk factors for severe illness (3-5). The virus enters cells through angiotensin converting enzyme (ACE)-2 receptors on cell membranes, and these receptors are present abundantly in type 2 pulmonary alveolar cells, resulting in predominant lung infection. ACE-2 receptors are ubiquitous, and are present in myocardium, gastrointestinal tract, liver, pancreas, and kidney (6). Gastrointestinal symptoms are reported in $2 \%$ to $33 \%$ of cases (7) and are most commonly abdominal pain, diarrhea, nausea, and vomiting. It is postulated that involvement of hepatocytes and biliary epithelial cells by the virus could be one the pathways causing abnormal liver enzymes and varying degrees of liver dysfunction $(5,6)$. Biliary epithelial cells express ACE-2 receptors at a concentration 20 times higher than hepatocytes (8). Only a limited number of studies have investigated the occurrence and pattern of liver disease with COVID-19 infection. We present the following review article in accordance with the Narrative Review reporting checklist (available at https://tgh.amegroups.com/article/ view/10.21037/tgh-20-243/rc).

\section{Pattern of liver injury in COVID-19 infection}

COVID-19 associated liver injury is defined as any liver damage occurring during disease progression and treatment of COVID-19 in patients with or without pre-existing liver diseases (5). Abnormal liver associated enzymes (LAEs) are reported in $16 \%$ to $83 \%$ of cases in different series (Table 1). Most studies report elevation in transaminases in about $37 \%$ and elevation in total bilirubin in about $10 \%$ of cases $(3,4)$. Severe hepatitis has been reported, but acute or acute on chronic liver failure has not been reported. In general, higher transaminase levels are seen in patients with greater COVID severity, especially in patients admitted to the intensive care unit (ICU). The elevation in transaminases is usually less than 2 times the upper limit of normal (ULN) in $95 \%$ of cases, and elevations greater than 5 times ULN are rare (13-16). This pattern of abnormal LAEs is comparable to that reported with the two previous influenza pandemics (28), although a recent report suggests abnormal LAEs may be more prevalent than previously reported depending upon when they are measured in the course of COVID-19 infection (27). In this recent report, more patients had abnormal LAEs when measured at peak hospitalization, as compared to baseline and admission measurements (27). About one third of patients with Severe Acute Respiratory Syndrome (SARS) or Middle East Respiratory Syndrome (MERS) infection had abnormal LAEs (28).

Huang et al., in a single center study of 41 patients with COVID-19 reported preexisting liver disease in only 2 patients, and 15 (37\%) patients had elevated transaminases. Among the patients admitted in non-ICU wards, $25 \%$ had elevated aspartate transaminase (AST), whereas $62 \%$ admitted to the ICU had elevated transaminases (3). Median albumin in patients admitted to the ICU was $2.79(2.63-3.09) \mathrm{g} / \mathrm{dL}$ and for those not admitted to the ICU was $3.47(3.02-3.65) \mathrm{g} / \mathrm{dL}, \mathrm{P}=0.0006$. It is not known whether the decrease in albumin is due to an acute phase response or hepatocellular dysfunction. In a large study of 1,099 patients, elevated alanine transaminase (ALT) was noted in $21.3 \%$, elevated AST was noted in $22.2 \%$, and elevated total bilirubin was noted in $10.5 \%$ (4). Higher values of AST, ALT, and total bilirubin were noted in those with severe disease and those meeting the primary composite end point of the study (admission to an ICU, use of mechanical ventilation, or death) $(15,21,25,26,27)$. Wang et al., in a study of 333 patients with COVID-19 from Wuhan medical center, noted abnormal LAEs in $39.6 \%$; the majority $(71.2 \%)$ had only mild elevation in LAEs. Twelve patients had a history of chronic hepatitis B (HBV), and 2 patients had a history of chronic hepatitis $\mathrm{C}(\mathrm{HCV})$, but all were negative on PCR testing (14). This study, however, found no difference between patients admitted to ICUs $(45.6 \%, 26 / 57)$ and general hospital wards $(38.4 \%, 106 / 276)$ $(\mathrm{P}>0.05)$. Other studies, including the case series by Fang

\footnotetext{
${ }^{1}$ We reviewed all relevant publications (searched in Scopus, PubMed and Google Scholar) in English literature on COVID-19 till Aug 15, 2020 .
} 


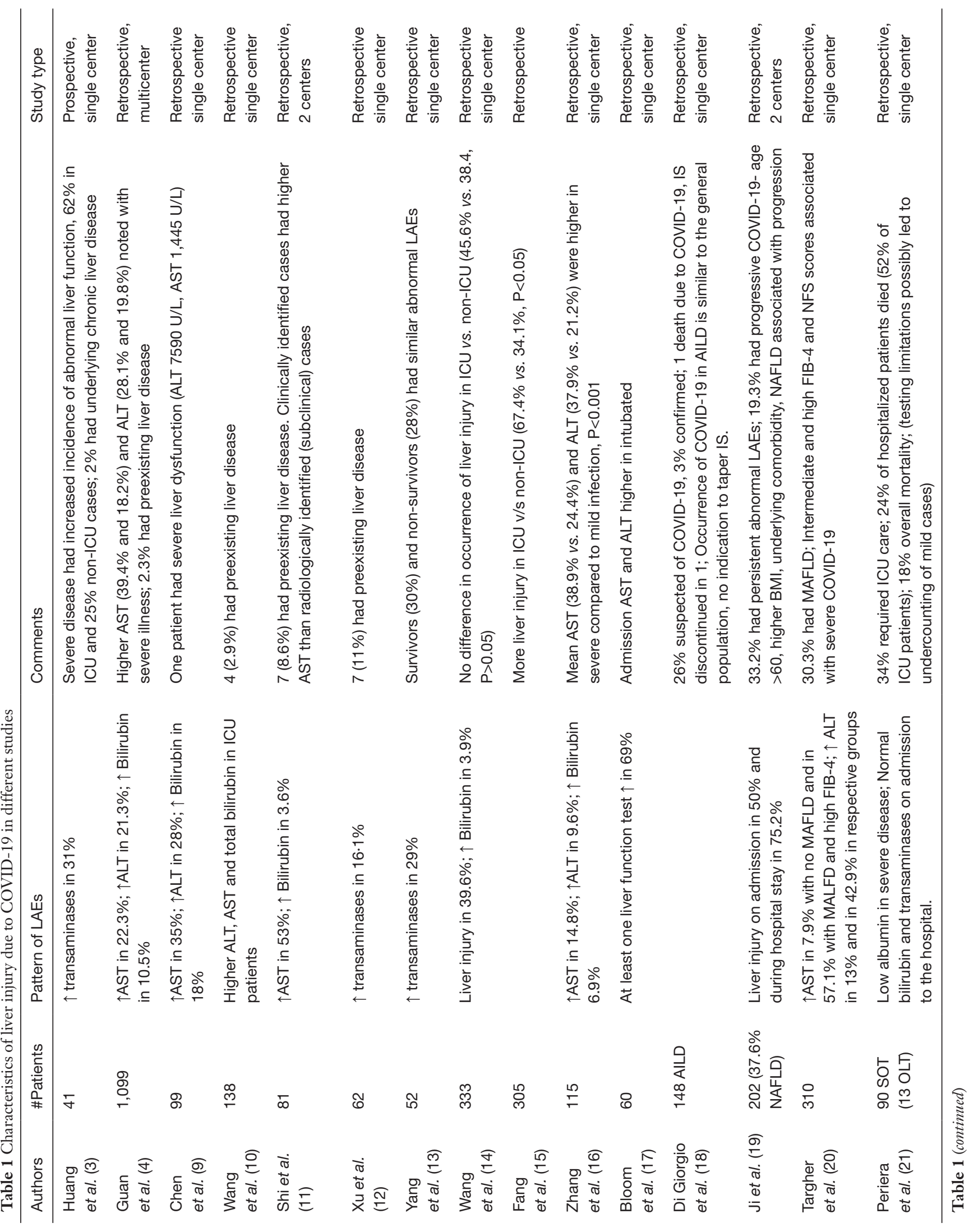




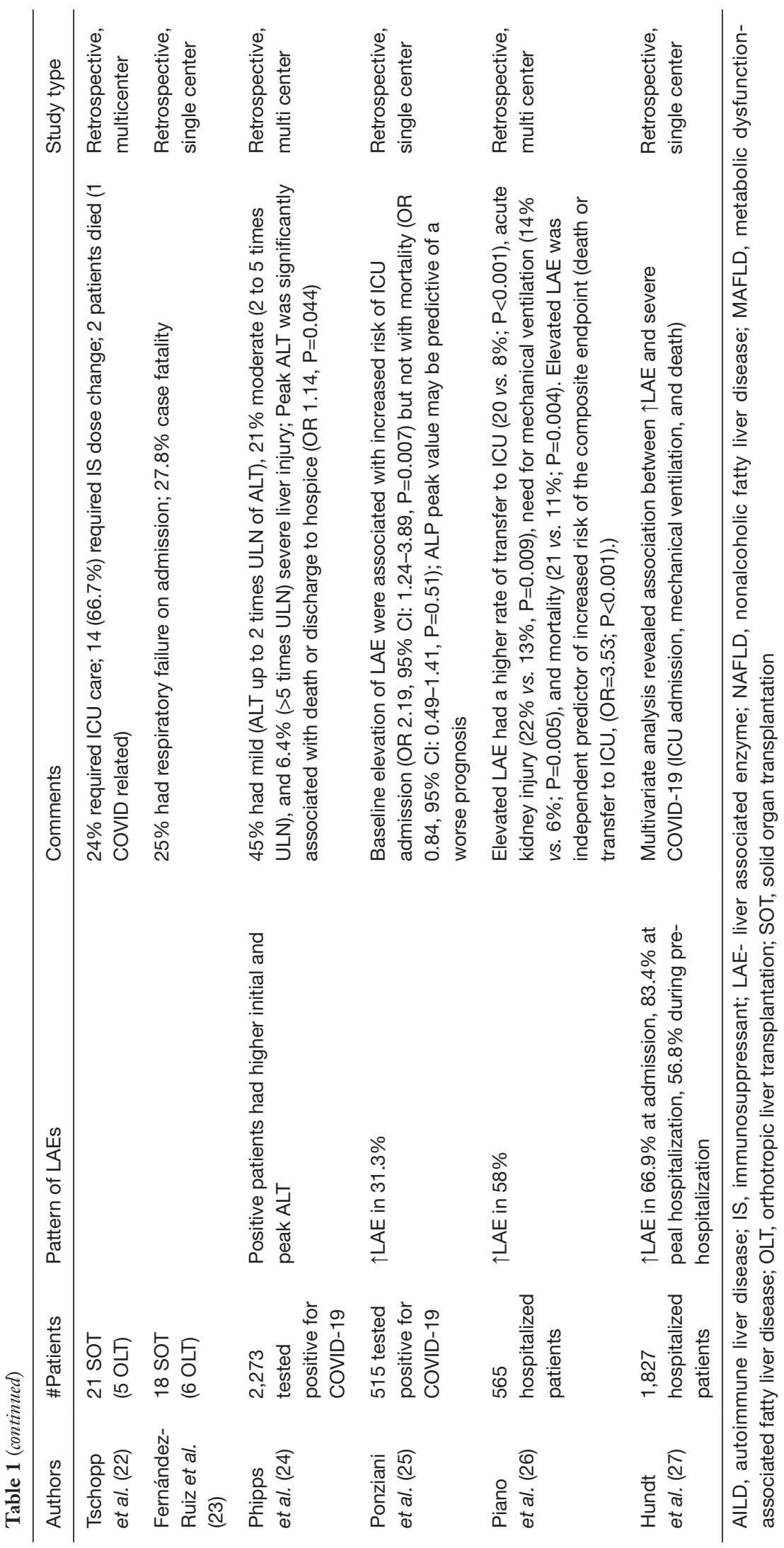


et al., noted a higher incidence of liver dysfunction in ICU patients $(67.4 \%$ vs. $34.1 \%, \mathrm{P}<0.05)(15)$. Zhang et al. studied the pattern of LAEs in 119 patients with COVID-19 and compared it with the same number of patients hospitalized with community acquired pneumonia in the previous year (16). Changes in LAEs were comparable in two groups, however, lower albumin levels were noted in the COVID group. Furthermore, in the COVID group albumin levels decreased further with progression into severe disease, suggesting that albumin may be a marker of disease severity. Bloom et al. analyzed LAEs in 60 COVID-19 patents who were hospitalized, and they reported AST-dominant aminotransferase elevation in 69\%, which paralleled disease severity and appeared to reflect true hepatic injury (17). In a retrospective multicenter study by Piano et al. $(\mathrm{n}=565)$, authors noted elevated LAE in $58 \%$ of admitted patients, those with elevated LAE had a higher rate of transfer to ICU, acute kidney injury, need for mechanical ventilation, and mortality. In multivariate analysis, patients with elevated LAE had increased risk of the composite endpoint (death or transfer to ICU) (26). In another study from China, authors reported severe COVID-19 illness among patients with metabolic dysfunction-associated fatty liver disease (MAFLD) with intermediate or high FIB-4 and NAFLD fibrosis scores (NFS) (19). On multivariate analysis, increasing FIB-4 and NFS were significantly associated with greater COVID-19 severity, even after adjusting for sex, obesity, diabetes, and presence/absence of MAFLD.

\section{Pathogenesis of liver injury}

Liver dysfunction in COVID-19 patients is postulated to be due to (I) immune mediated damage in the setting of intense inflammatory activity and cytokine storm, (II) direct virally-induced hepatotoxicity, (III) hypoxia induced liver injury, (IV) drug induced liver injury (DILI), (V) sinusoidal congestion related to positive pressure ventilation, (VI) reactivation of pre-existing liver disease and (VII) hepatic microvascular changes and microthrombi formation due to intense systemic inflammation $(28,29)$. Liver biopsy from a COVID-19 infected patient revealed moderate microvascular steatosis and mild lobular and portal activity (30). This could be suggestive of either direct cytotoxicity due to viral infection or drug induced liver injury (or background nonalcoholic fatty liver disease). In a recent study from Italy, post-mortem wedge liver biopsies from 48 patients who died from COVID-19 disease with respiratory failure were analyzed. None had symptoms or signs of liver disease prior to or during hospitalization. Biopsies showed minimal inflammation. Changes suggestive of vascular alterations characterized by increase in number and size of portal vein branches, partial or complete luminal thrombosis of portal and sinusoidal vessels, and fibrosis of portal tracts were observed. SARS-CoV-2 was found in 15 of 22 samples in blood clot or endothelial cells by in situ hybridization testing. It is unclear if these changes are directly related to virus infection or secondary to vascular alterations following cytokine storm (29). In another report of liver biopsy (postmortem), sinusoidal dilatation and lymphocytic infiltration were reported (16). Liver biopsy should be considered only if there is a strong suspicion of a coincidental additional pathology, like acute cellular rejection, rather than COVID infection itself. Elevated inflammatory biomarkers including $\mathrm{C}$-reactive protein (CRP), serum ferritin, lactate dehydrogenase, D-dimer, interleukin-6, and interleukin-2 are elevated in COVID-19 patients, with higher levels seen in those with severe infection (5). Since ACE-2 is directly expressed in biliary epithelial cells, there could be direct cytotoxicity from viral activity. SARS-CoV-2 has been isolated from stools and the implication of this on pathogenesis of GI or liver disease is not clear (31). Hypoxia-induced hepatitis could be a preterminal event in severe illness, and significant respiratory and cardiac failure due to any etiology can cause elevated LAEs (5). Varying degrees of DILI have been reported with disease-specific antiviral agents used in the treatment of COVID-19. Azithromycin, lopinavir/ritonavir, remdesivir, chloroquine, tocilizumab, and Chinese traditional medicines have all been attributed to cause DILI of varying severity (Table 2). Liver function is susceptible to impeded venous return and sinusoidal congestion, resulting from increased intra-thoracic pressure during mechanical ventilation, and abnormal LAEs are known to occur in these patients. High levels of positive end expiratory pressure can contribute to hepatic congestion by increasing right atrial pressure $(34,35)$. $\mathrm{HBV}$ and $\mathrm{HCV}$ predispose patients to more severe liver injury with SARS, but so far there are no similar reports with COVID-19 (36).

\section{Management of patients with liver disease and CovID-19 infection}

Most guidelines recommend continuing follow up of patients with preexisting chronic conditions [including chronic liver disease (CLD)] and avoiding hospital 
Table 2 Occurrence of drug induced liver injury and interactions with immunosuppressant agents with disease specific drugs for COVID-19

\begin{tabular}{|c|c|c|}
\hline Medication & Probability of drug induced liver injury & Interactions with immune suppressants ${ }^{\#}(32)$ \\
\hline \multirow{3}{*}{ Lopinavir/ritonavir } & & C levels can increase* \\
\hline & & M levels can increase or decrease* \\
\hline & & $S$ levels can increase (should not be co-administered) ${ }^{*}$ \\
\hline \multirow[t]{3}{*}{ Chloroquine } & Likelihood score: D & No changes with $A, B$ and $M$ \\
\hline & $\begin{array}{l}\text { no hepatotoxicity } \\
\text { (elevated transaminases reported with AIP, PCT) }\end{array}$ & C levels can increase ${ }^{*}$ \\
\hline & & S levels can increase ${ }^{*}$ \\
\hline Azithromycin & QTc prolongation with chloroquine and hydroxychloroquine & \\
\hline \multirow[t]{2}{*}{ Remdesivir } & $\begin{array}{l}\text { Considered safe, cannot be administered if } \\
\text { transaminases are more than } 5 \text { times ULN }\end{array}$ & A levels can increase ${ }^{*}$ \\
\hline & & No changes with $B, C, M, S, T$ \\
\hline \multirow[t]{3}{*}{ Tocilizumab } & Likelihood score: D & $\mathrm{C}, \mathrm{S}$ and $\mathrm{T}$ levels can decrease ${ }^{\star}$ \\
\hline & No reactivation of hepatitis $B$ & B should not be co-administered \\
\hline & Mild worsening of LAEs in those with hepatitis $C$ & No changes with A,M \\
\hline \multicolumn{3}{|c|}{$\begin{array}{l}\text { *, Potential interaction which may require dose adjustment or close monitoring; }{ }^{\#}, \mathrm{~A} \text {, azathioprine, B, Basiliximab, C, Cyclosporin, M, } \\
\text { mycophenolate, S, sirolimus, T, tacrolimus (as per University of Liverpool drug interaction data base). AIP, acute intermittent porphyria, } \\
\text { PCT, porphyria cutanea tarda, VBS, vanishing bile duct syndrome; ACR, acute cellular rejection. Likelihood score: D, possible, rare cause } \\
\text { of clinically apparent liver injury, LiverTox database (33); Likelihood score: A, well known cause of clinically apparent liver injury, LiverTox } \\
\text { database. }\end{array}$} \\
\hline
\end{tabular}

visits, unless clinically indicated (37). Telephone and telemedicine clinics are extremely helpful in this setting. While evaluating patients with COVID-19 and abnormal LAEs, other causes of liver disease such as MAFLD, alcohol related liver disease, and chronic HCV and HBV should always be considered in the appropriate clinical setting based on the local prevalence of these conditions and individual susceptibility. One should also consider myositis as a cause of predominantly elevated AST in patients with ischemia and cytokine release syndrome $(5,38)$. It is not clear if COVID-19 will worsen cholestasis in those with cholestatic liver disease (37). High grade fever is a consistent feature of COVID-19 and acetaminophen up to $3 \mathrm{~g} / \mathrm{day}$ is safe and recommended, even in patients with chronic and acute liver injury. Elevated LAEs due to COVID-19 are usually transient, and LAEs return to normal with recovery (38). Most of the disease specific drugs used for treatment of COVID-19 are relatively safe and their use should not be discouraged even with abnormal LAEs. The American Association for the Study of Liver Diseases (AASLD) recommends regular monitoring of LAEs in COVID-19 patients in general and in those on disease specific drugs (37). While evaluating new onset abnormal LAEs inpatients with COVID-19 and autoimmune hepatitis or post liver transplantation, acute flare and acute cellular rejection, respectively, should always be considered. 
Appropriate investigations including immunosuppressant dose levels will help in ascertaining the cause of elevated LAEs. Di Giorgi et al., in a follow up of 148 patients with autoimmune liver disease (AILD) on immunosuppression (IS), observed suspected COVID-19 in 26\% and proven COVID-19 in 3\%. There was 1 death related to COVID-19, and 1 patient required discontinuation of IS dose. Authors concluded that the occurrence of COVID-19 in AILD was similar to the general population, in the absence of major complications due to COVID-19 there was no indication to taper or discontinue IS and the overall outcome was favorable in majority of cases (18). Management of patients with hepatocellular carcinoma (HCC) should proceed without interruption. However, a slight delay in surveillance for HCC by one or two months will be unavoidable in most centers and this should not affect overall care, given the slow doubling time of HCC.

CLD was identified as a risk factor for hospitalization from a large electronic database study of more than 17 million patients (>114,000 with CLD) from the UK (39). In another large study of 2,780 patients from the US, CLD was identified as a risk factor for death in COVID-19 patients (40). In a recent analysis of data of patients with CLD and COVID-19 from two international reporting registries (COVID-Hep.net and COVIDCirrhosis.org; involving 21 countries, total of 152 patients with CLD, 103 cirrhotics), authors reported $12.2 \%$ mortality in CLD without cirrhosis, $23.9 \%$ in CTP-A cirrhosis, $43.3 \%$ in CTP-B cirrhosis, and $63.0 \%$ in CTP-C cirrhosis. CTP-B and CTP-C cirrhosis were associated with mortality after adjusting for baseline characteristics including comorbidities (41). In this study group, the cause of death was pulmonary in $78.7 \%$ and liver related in $12.1 \%$. Hepatic decompensation occurred in $36.9 \%$ and was associated with $63.2 \%$ mortality (compared to $26.2 \%$ mortality in those without hepatic decompensation). One fourth of patients with new onset hepatic decompensation had no respiratory symptoms at the time of diagnosis. These studies indicate that CLD increases the risk of severe COVID-19 infection and mortality.

\section{Liver transplantation and COVID-19}

The COVID-19 pandemic raises significant challenges with liver transplantation. The United Network for Organ Sharing (UNOS) has not recommend postponement of transplant evaluation and/or surgeries due to COVID-19. UNOS has encouraged local organ recovery (42). The
American Society of Transplantation recommends using discretion for solid organ transplantation, based on COVID-19 prevalence in recipient and donor areas, donor and recipient risk for COVID-19 disease, and availability of testing facilities and resources for recipient care (43). COVID-19 patients are not eligible for organ donation. It is important to remember that transplant recipients tend to have a greater COVID-19 viral burden and prolonged viral shedding which can lead to greater infectivity and chance of spread (43). So far, there are no recommendations to reduce the dose of a stable IS regimen to decrease the risk of acquiring COVID-19 infection. In infected patients receiving disease specific antivirals, IS doses may have to be altered to avoid drug-drug interactions, guided by IS dose levels (Table 2). It is extremely important for non-infected immune suppressed patients to strictly adhere to personal hygiene and social distancing recommendations.

The course and progression of COVID-19 in immunosuppressed patients is still unclear. From reported experiences with the two previous Corona virus pandemics, it seems unlikely that COVID-19 would have a more severe course in post-transplant patients. In the previous two influenza pandemics, SARS and MERS, no fatality was reported in patients undergoing transplantation, chemotherapy, or other immunosuppressive treatments, at any age (28). D'Antiga et al., from a pediatric liver transplant center in Bergamo, Italy, reports no increased mortality in their study group (28). They report only 3 positive cases among more than two hundred post-transplant patients.

Immunosuppressed solid organ transplant (SOT) recipients could be more susceptible to COVID-19 and severe illness, but the anti-inflammatory response is significantly blunted in these patients $(28,44)$. The calcineurin inhibitors (CNI) reduce the production of interleukin-2 (IL-2), a regulator of T-cell proliferation, survival, and maturation. Tacrolimus and mycophenolic acid inhibit interleukin-17 (IL-17) production with a stronger inhibitory effect on Th17 cells (44). Since over activation of T-cells results in lung injury, IS could theoretically alter the clinical course and severity of lung injury in SOT recipients. However, it is premature to assume that IS could be a protective factor or a therapeutic choice. There is a reported case of severe uncontrolled infection in a post liver transplant patient with COVID-19 who succumbed to illness (45). Bhoori et al. reports three deaths in a follow-up study of 111 patients from Lombardy, Italy. All three had other significant comorbidities and were more than 10 years post-transplant with stable, low IS regimens. It appears 
that these comorbid conditions were the cause of the fatal outcomes in these patients (46). The authors suggest that in long-term post-transplant patients, metabolic conditions may be a stronger driver of poor outcomes than IS status itself. In a recent report of 90 SOT recipients (13 had liver transplantation) from the US, $27(30 \%)$ had severe disease; 23 (26\%) required ICU admission and $16(18 \%)$ died. Interestingly none of these patients had abnormal bilirubin or transaminases at the time of hospital admission and none had acute graft rejection during the course of illness (21). Another report of COVID-19 in 21 SOT recipients from Switzerland showed similar outcomes in SOT recipients as compared to the general population (22). Secure-cirrhosis database, an international registry of COVID-19 infected patients with CLD or a liver transplant, includes submissions from 34 countries across the globe (last updated on July 14, 2020). This registry reports $19 \%$ mortality in liver transplant recipients (total $\mathrm{n}=160$ ), $33 \%$ mortality in patients with cirrhosis (total $\mathrm{n}=425$ ) and $7 \%$ mortality in patients with CLD without cirrhosis (total $n=372$ ) (47). The Beijing working party for liver transplantation recommends continuing the same dose of IS for mild to moderate COVID-19 infections and individualizing IS treatment for severe infections (48). The AASLD recommends a similar strategy and advises dose reduction of antimetabolites (azathioprine, mycophenolate) and CNIs (but not discontinuation of CNI) in those with fever, lymphopenia and worsening pulmonary disease due to COVID-19.

\section{Conclusions}

COVID-19 is a constantly changing landscape. The standard of care for liver patients must not be compromised by the pandemic, but the current limitations are formidable. Telemedicine or phone clinics to ensure continued follow up, reiterating recommendations for social distancing and avoiding sick contacts, and in selected cases, in-person clinic or hospital visits will facilitate safe patient care. There are many unanswered questions regarding this pandemic, the long-term outcome of biliary and hepatocyte invasion of the virus, implications of fecal shedding of viral RNA, the chances that immunosuppressed individuals with high viral load could be persistent or long term carriers of infection. CLD appears to be a risk factor for acquiring COVID-19 infection and death, and patients with decompensated cirrhosis seem to have the poorest outcome. The course of COVID-19 in post liver transplant patients is variable, but recent reports indicate higher mortality in these patients compared to the general population. As more data continues to emerge from the pandemic, our understanding of the disease will improve.

\section{Acknowledgments}

Funding: None.

\section{Footnote}

Reporting Checklist: The authors have completed the Narrative Review reporting checklist. Available at https:// tgh.amegroups.com/article/view/10.21037/tgh-20-243/rc

Peer Review File: Available at https://tgh.amegroups.com/ article/view/10.21037/tgh-20-243/prf

Conflicts of Interest: All authors have completed the ICMJE uniform disclosure form (available at https://tgh.amegroups. com/article/view/10.21037/tgh-20-243/coif). The authors have no conflicts of interest to declare.

Ethical statement: The authors are accountable for all aspects of the work in ensuring that questions related to the accuracy or integrity of any part of the work are appropriately investigated and resolved.

Open Access Statement: This is an Open Access article distributed in accordance with the Creative Commons Attribution-NonCommercial-NoDerivs 4.0 International License (CC BY-NC-ND 4.0), which permits the noncommercial replication and distribution of the article with the strict proviso that no changes or edits are made and the original work is properly cited (including links to both the formal publication through the relevant DOI and the license). See: https://creativecommons.org/licenses/by-nc-nd/4.0/.

\section{References}

1 Johns Hopkins Coronavirus Resource Center. Accessed: August 14, 2020. Available online: http://Coronavirus.jhu. edu

2 Zhu N, Zhang D, Wang W, et al. A Novel Coronavirus from Patients with Pneumonia in China, 2019. N Engl J Med 2020;382:727-33.

3 Huang C, Wang Y, Li X, et al. Clinical features of patients infected with 2019 novel Corona virus in Wuhan, China. 
Lancet 2020;395:497-506.

4 Guan WJ, Ni ZY, Hu Y, et al. Clinical characteristics of Coronavirus 2019 in China. N Engl J Med 2020;382:1708-20.

5 Sun J, Aghemo A, Forner A, et al. COVID-19 and liver disease. Liver Int 2020;40:1278-81.

6 Hamming I, Timens W, Bulthuis MLC, et al. Tissue distribution of ACE2 protein, the functional receptor for SARS coronavirus. A first step in understanding SARS pathogenesis. J Pathol 2004;203:631-7.

7 Ng SC, Tilg H. COVID-19 and the gastrointestinal tract: more than meets the eye. Gut 2020;69:973-4.

8 Guan GW, Gao L, Wang JW, et al. Exploring the mechanism of liver enzyme abnormalities in patients with novel Coronavirus infected pneumonia. Zhonghua Gan Zang Bing Za Zhi 2020;28:100-6.

9 Chen N, Zhou M, Dong X, et al. Epidemiological and clinical characteristics of 99 cases of 2019 novel Coronavirus pneumonia in Wuhan, China: a descriptive study. Lancet 2020;395:507-13.

10 Wang D, Hu B, Hu C, et al. Clinical characteristics of 138 hospitalized patients with 2019 novel Coronavirus-infected pneumonia in Wuhan, China. JAMA 2020;323:1061-9.

11 Shi H, Han X, Jiang N, et al. Radiological findings from 81 patients with COVID-19 pneumonia in Wuhan, China: a descriptive study. Lancet Infect Dis 2020;20:425-34.

$12 \mathrm{Xu} X W, \mathrm{Wu}$ XX, Jiang XG, et al. Clinical findings in a group of patients infected with the 2019 novel Coronavirus (SARS-Cov-2) outside of Wuhan, China: retrospective case series. BMJ 2020;368:m606.

13 Yang X, Yu Y, Xu J, et al. Clinical course and outcomes of critically ill patients with SARS-CoV-2 pneumonia in Wuhan, China: a single-centered, retrospective, observational study. Lancet Respir Med 2020;8:475-81.

14 Wang SH, Han P, Xiao F, et al. Manifestations of liver injury in 333 hospitalized patients with Coronavirus disease 2019. Chinese Journal of Digestion 2020;40:157-61.

15 Fang D, Ma JD, Guan JL, et al. Manifestations of digestive system in hospitalized patients with novel coronavirus pneumonia in Wuhan, China: a single-center, descriptive study. Chinese Journal of Digestion 2020;40:151-6.

16 Zhang $\mathrm{Y}$, Zheng L, Liu L, et al. Liver impairment in COVID-19 patients: a retrospective analysis of 115 cases from a single center in Wuhan city, China. Liver Int 2020;40:2095-103.

17 Bloom PP, Meyerowitz EA, Reinus Z, et al. Liver Biochemistries in Hospitalized Patients With COVID-19. Hepatology 2021;73:890-900.
18 Di Giorgio A, Nicastro E, Speziani C, et al. Health status of patients with autoimmune liver disease during SARS-CoV-2 outbreak in northern Italy. J Hepatol 2020;73:702-5.

19 Ji D, Qin E, Xu J, et al. Non- alcoholic fatty liver diseases in patients with COVID-19: A retrospective study. J Hepatol 2020;73:451-3.

20 Targher G, Mantovani A, Byrne CD, et al. Risk of severe illness from COVID-19 in patients with metabolic dysfunction associated fatty liver disease and increased fibrosis scores. Gut 2020;69:1545-7.

21 Pereira MR, Mohan S, Cohen DJ, et al. COVID-19 in solid organ transplant recipients: Initial report from the US epicenter. Am J Transplant 2020;20:1800-8.

22 Tschopp J, L'Huillier AG, Mombelli M, et al. First experience of SARS-CoV-2 infections in solid organ transplant recipients in the Swiss Transplant Cohort Study. Am J Transplant 2020;20:2876-82.

23 Fernández-Ruiz M, Andrés A, Loinaz C, et al. COVID-19 in Solid Organ Transplant Recipients: A Single-Center Case Series From Spain. Am J Transplant 2020;20:1849-58.

24 Phipps MM, Barraza LH, LaSota ED, et al. Acute Liver Injury in COVID-19: Prevalence and Association with Clinical Outcomes in a Large US Cohort. Hepatology 2020;72:807-17.

25 Ponziani FR, Zompo F, Nesci A, et al. Liver involvement is not associated with mortality: results from a large cohort of SARS-CoV-2 positive patients. Aliment Pharmacol Ther 2020;52:1060-8.

26 Piano S, Dalbeni A, Vettore E, et al. Abnormal liver function tests predict transfer to intensive care unit and death in COVID-19. Liver Int 2020;40:2394-406.

27 Hundt MA, Deng Y, Ciarleglio MM, et al. Abnormal Liver Tests in COVID-19: A Retrospective Observational Cohort Study of 1827 Patients in a Major U.S Hospital Network. Hepatology 2020;72:1169-76.

28 D'Antiga L. Coronaviruses and Immunosuppressed Patients: The Facts During the Third Epidemic. Liver Transpl 2020;26:832-4.

29 Sonzogni A, Previtali G, Seghezzi M, et al. Liver histopathology in severe COVID 19 respiratory failure is suggestive of vascular alterations. Liver Int 2020;40:2110-6.

$30 \mathrm{Xu}$ Z, Shi L, Wang Y, Zhang J, et al. Pathological findings of COVID-19 associated with acute respiratory distress syndrome. Lancet Respir Med 2020;8:420-2.

31 Holshue ML, DeBolt C, Lindquist S, Lofy KH, Wiesman J, Bruce H, et al. First case of 2019 novel coronavirus in 
the United States. N Engl J Med 2020;382:929-36.

32 Covid-19 drug interactions in University of Liverpool data base. Available online: www.covid19-druginteractions.org/

33 LiverTox. Clinical and Research Information on DrugInduced Liver Injury. Bethesda (MD): National Institute of Diabetes and Digestive and Kidney. 2012.

34 Sun G, Chen J, Uyang B, et al. Liver function is affected by mechanical ventilation after abdominal surgery. J Am College Surg 2013;217: S56-7.

35 Bangash MN, Patel J, Parekh D. COVID-19 and the liver: little cause for concern. Lancet Gastroenterol Hepatol 2020;5:529-30.

$36 \mathrm{Xu}$ L, Liu J, Lu M, et al. Liver injury during highly pathogenic human Coronavirus infections. Liver Int 2020;40:998-1004.

37 AASLD COVID-19 update. Available online: https://www. aasld.org/sites/default/files/2020-06/AASLD-COVID19ExpertPanelConsensusStatement-June252020-v2-FINAL.pdf

38 Zhang C, Shi L, Wang FS. Liver injury in COVID-19: Management and challenges. Lancet Gastroenterol Hepatol 2020;5:428-30.

39 The Open SAFELY Collaborative, Williamson E, Walker AJ, et al. Open SAFELY: factor associated with COVID19-related hospital death in the linked electronic health records of 17 million adult NHS patients. medRxiv 2020. (published online May 7). (preprint). DOI: 10.1101/2020.05.06.20092999

40 Singh S, Khan A. Clinical Characteristics and Outcomes of Coronavirus Disease 2019 Among Patients With

doi: $10.21037 /$ tgh-20-243

Cite this article as: Thandassery RB, Dranoff JA, Perisetti A, Taddei T. COVID-19 and the liver: a narrative review of the present state of knowledge. Transl Gastroenterol Hepatol 2022;7:40.
Preexisting Liver Disease in the United States: A Multicenter Research Network Study. Gastroenterology 2020;159:768-71.e3.

41 Moon AM, Webb GJ, Aloman C, et al. High mortality rates for SARS-CoV-2 infection in patients with preexisting chronic liver disease and cirrhosis: Preliminary results from an international registry. J Hepatol 2020;73:705-8.

42 COVID-19 and solid organ transplant. Available online: https://unos.org/covid/

43 American Society of Transplantation 2019-nCoV (Coronavirus): FAQs for organ donation and transplantation. 2020.

44 Abadja F, Atemkeng S, Alamartine E, et al. Impact of mycophenolic acid and tacrolimus on Th17-related immune response. Transplantation 2011;92:396-403.

45 Huang JF, Zheng KI, George J, et al. Fatal outcome in a liver transplant recipient with COVID-19. Am J Transplant 2020;20:1907-10.

46 Bhoori S, Rossi RE, Citterio D, et al. COVID-19 in longterm liver transplant patients: preliminary experience from an Italian transplant centre in Lombardy. Lancet Gastroenterol Hepatol 2020;5:532-3.

47 SECURE-Cirrhosis. Available online: https:// covidcirrhosis.web.unc.edu/

48 Liu H, He X, Wang Y, et al. Management of COVID-19 in patients after liver transplantation: Beijing working party for liver transplantation. Hepatol Int 2020;14:432-6. 